\title{
Frequency of Neonatal Hypoglycemia Among Women Diagnosed with Maternal Hyperglycemia
}

\author{
HUMAIRA ASHRAF ${ }^{1}$, MEHREEN YOUSAF RANA ${ }^{2}$, AFRA REHMAN ${ }^{3}$, ANILA MAHMOOD \\ ${ }^{1}$ Assistant Professor, Department of Pathology, NICVD Karachi \\ ${ }^{2}$ Assistant professor, Gynae and OBS, Dr. Ziauddin Hospital Clifton Karachi \\ ${ }^{3}$ Assistant professor, Gynae and OBS, PUMHS for women Shaheed Benazirabad \\ ${ }^{4}$ Assistant professor, Gynae and OBS, LUMHS Jamshoro \\ Correspondence to: Humaira Ashraf, Email: drhumaira1@icloud.com
}

\begin{abstract}
Objective: To determine frequency of neonatal hypoglycemia, in maternal hyperglycemia

Subject and Method: This cross-sectional study was conducted at department of Pathology with collaboration of gynae and OBS department of PNS SHIFA Karachi. Study duration was six months from March 2015 to August 2015. All pregnant women who reported at antenatal clinics of PNS SHIFA Hospital and diagnosed as the cases of hyperglycinemia were included in the study. Maternal blood glucose testing was done according to WHO guidelines i.e. fasting sample, ingestion of $75 \mathrm{~g}$ glucose, $01 \mathrm{~h}$ and $02 \mathrm{~h}$ sample for plasma glucose estimation. Neonatal blood glucose was checked immediately after birth by glucometer.

All the data was collected via study proforma.

Results: A total of 157 pregnant women were studied their average age was $28.20 \pm 4.67$ years. Caesarean section was done in $62.4 \%$ cases and $58.6 \%$ babies were males. Neonatal hypoglycemia was observed among $24.8 \%$ of the cases. Neonatal hypoglycemia was statistically significant according to gestational age $(p-0.012)$, while statistically insignificant according to parity ( $p-0.184)$.

Conclusion: As per study conclusion, the neonatal hypoglycemia was observed to be highly prevalent among neonates of diabetic mothers as $24.8 \%$. It was found to be statistically significant according to gestational age.

Keywords: Gestational diabetes mellitus, Neonates, Hypoglycemia
\end{abstract}

\section{INTRODUCTION}

Gestational diabetes mellitus (GDM) is characterized as the intolerance of the glucose of variable severity with beginning or first rise during the pregnancy. ${ }^{1}$ Worldwide GDM affects $0.6 \%-15 \%$ of all pregnancies annually whereas, in Pakistan, a prevalence of $8 \%$ has been found in Karachi. ${ }^{2,3}$ There are however, many gray areas in diagnosis and treatment of hyperglycemia in pregnancy. It has been suggested, however, that current diagnostic criteria for GDM have disadvantage of missing potential adverse pregnancy outcomes as a result of lesser degrees of elevated glucose level that is less severe than that diagnostic of GDM (mentioned above).4-6 These criteria for GDM diagnosis were recognized above 40 years ago and poorly identify the females during pregnancy who are at high risk for adverse neonatal outcomes. ${ }^{8}$ Gestational impaired glucose tolerance (GIGT) is a condition in which two hours postglucose load level is elevated $(7.8-11.1 \mathrm{mmol} / \mathrm{L})$ during an Oral Glucose Tolerance Test (OGTT). ${ }^{7}$ But there is no consensus on diagnostic criteria of GIGT. Another category of hyperglycemia called impaired fasting glucose (IFG) has yet not been studied in relation to pregnancy outcomes. Similarly, one-hour post-glucose (1hPG) has not been categorized. On the other hand, a large-scale recent study on maternal hyperglycemia and adverse pregnancy outcome (HAPO) has concluded that strong and continuous associations exists between levels of maternal glucose below those diabetes diagnosis and elevated birth weight and raises in the levels of cord-blood serum Cpeptide. ${ }^{9}$ Similarly, GIGT has also been shown to be associated with increased rate of cesarean delivery. ${ }^{10,11}$ Diabetes of the mothers, which is related to high blood glucose levels (hyperglycemia), is one such compromising climate; overabundance glucose is shunted into the system of fetus which then, at that point should make variations to the adjusted environment. ${ }^{12}$ This outcome results in various fetal, neonatal, and post pregnancy consequences for the neonates, which becomes the basis for varied short term and long-term complications in both mother and the baby. However, neonatal hypoglycemia has also been shown to be adverse fetal outcomes as a result of GDM. ${ }^{9}$ This study has been conducted to determine frequency of neonatal hypoglycemia, in maternal hyperglycemia even if maternal Oral Glucose Tolerance Test does not correspond to GDM

\section{MATERIALS AND METHODS}

This cross-sectional study was conducted at department of pathology with collaboration of gynae and OBS department of PNS SHIFA Karachi. Study duration was six months from March 2015 to August 2015. All pregnant women who reported at antenatal clinics of PNS SHIFA Hospital during 24-32 weeks of pregnancy, undergoing $75 \mathrm{gm} 2 \mathrm{~h}$ glucose tolerance test and fulfilling criteria of IFG, IGT OR GIGT were included in the study. All the women having age $<18$ years, females with pregnancy complicated by other illnesses like hypertension, any autoimmune disease, multiple pregnancy and women who were not agreeing to participate in the study were excluded. Informed consent was taken and purpose of research was explained to them. Blood glucose testing was done according to WHO guidelines i.e. fasting sample, ingestion of $75 \mathrm{~g}$ glucose, 01 $\mathrm{h}$ and $02 \mathrm{~h}$ sample for plasma glucose estimation. Data were noted in proforma of the study. Women were followed till delivery and outcomes mentioned above were noted. Glucose test was done by the researcher herself using glucose oxide method. Categories of women was made on the basis of plasma glucose: 
a. Category 1: Fasting Plasma Glucose $>5.3 \mathrm{mmol} / \mathrm{L}$ but 01 and $02 \mathrm{~h}$ post-load values less than 10.0 and $8.6 \mathrm{mmol} / \mathrm{L}$, respectively (Impaired Fasting Glucose)

b. Category 2: Fasting Plasma Glucose $<5.3 \mathrm{mmol} / \mathrm{L}$ 01 - hour post load value $>10 \mathrm{mmol} / \mathrm{L}$ but $02 \mathrm{~h}$ postload values less than $8.6 \mathrm{mmol} / \mathrm{L}$ (Gestational Impaired Glucose Tolerance).

c. Category 3: Fasting Plasma Glucose between 4.5 - 5.3 $\mathrm{mmol} / \mathrm{L}$ but $01 \mathrm{hr}$ post load value $>10 \mathrm{mmol} / \mathrm{Land} 02 \mathrm{~h}$ post-load values less than $8.6 \mathrm{mmol} / \mathrm{L}$.

d. Category 4: Fasting Plasma Glucose $<4.5 \mathrm{mmol} / \mathrm{L}$ but 01 and $02 \mathrm{~h}$ post-load values less than 10.0 and $8.6 \mathrm{mmol} / \mathrm{L}$, respectively.

e. Category 5: Fasting Plasma Glucose $<5.3 \mathrm{mmol} / \mathrm{L}$ but 01 or $02 \mathrm{~h}$ post-load values between $9.0-10$ $\mathrm{mmol} / \mathrm{L}$ and 7.6-8.6 $\mathrm{mmol} / \mathrm{L}$ respectively.

Confounding variables were removed by strictly following the exclusion criteria. However, patients showing higher results(values diagnostic of GDM) were informed regarding their results due to ethical reasons and excluded from study. Data was stored and analyzed in SPSS-20.

\section{RESULTS}

A total of 157 pregnant women were studied their average age was $28.20 \pm 4.67$ years, similarly average gestational age, fasting blood glucose, OGTT have also been presented in table 1.

Table 1. Descriptive statistics of maternal outcome $n=157$

\begin{tabular}{|c|c|c|}
\hline \multicolumn{2}{|l|}{ Variables } & Statistics \\
\hline \multicolumn{2}{|l|}{ Age (Years) } & $28.20 \pm 4.67$ \\
\hline \multicolumn{2}{|c|}{ Gestational Age (Weeks) } & $37.85 \pm 3.11$ \\
\hline \multicolumn{2}{|c|}{ Fasting Blood Glucose mmol/L } & $4.86 \pm 0.86$ \\
\hline \multicolumn{2}{|c|}{ 1-h OGTT mmol/L } & $7.55 \pm 1.71$ \\
\hline \multicolumn{2}{|l|}{ 2-h OGTT mmol/L } & $7.24 \pm 1.90$ \\
\hline \multirow{3}{*}{ Parity } & Primipara & $81(51.6 \%)$ \\
\hline & Multipara & $59(37.6 \%)$ \\
\hline & Grand multipara & $17(1.8 \%)$ \\
\hline \multirow[t]{2}{*}{ Mode of delivery } & Normal vaginal delivery & $59(37.6 \%)$ \\
\hline & C-section & $98(42.4 \%)$ \\
\hline \multirow{2}{*}{$\begin{array}{l}\text { Gender of delivered } \\
\text { babies }\end{array}$} & Male & $65(58.6 \%)$ \\
\hline & Female & $92(41.4 \%)$ \\
\hline
\end{tabular}

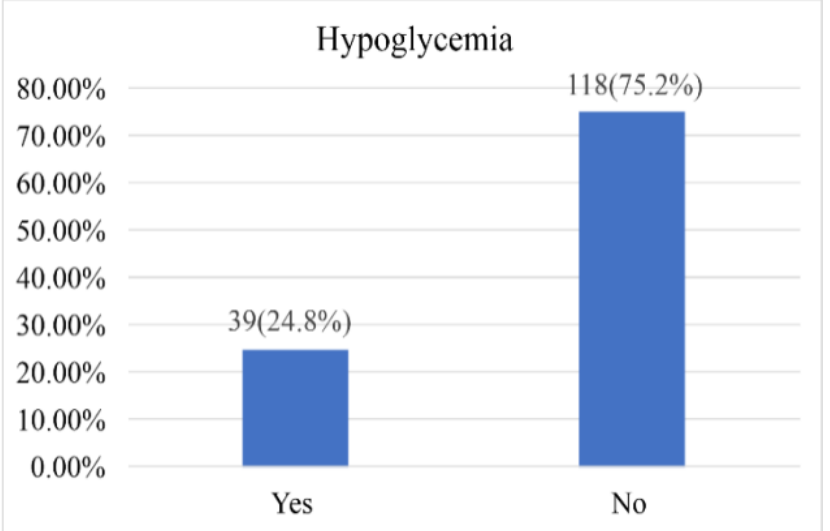

Fig: Frequency of hypoglycemia $n=157$
Out of all cases, $81(51.6 \%)$ were primipara, $59(37.6 \%)$ were multipara and $17(1.8 \%)$ were grand multipara. Caesarean section was done in 98(62.4\%) cases and $59(37.6 \%)$ were delivered by normal vaginal delivery. 92(58.6\%) babies were male and 65(41.4\%) were female.

Frequency of neonatal hypoglycemia was observed among $24.8 \%$ of the cases. Fig: 1

Neonatal hypoglycemia was statistically significant according to gestational age ( $p-0.012)$, while statistically insignificant according to parity $(p-0.184)$ as showed in table.2

Table:2 Neonatal hypoglycemia according to gestational age and parity $n=157$

\begin{tabular}{|c|c|c|c|c|}
\hline \multicolumn{2}{|l|}{ Variables } & \multicolumn{2}{|l|}{$\begin{array}{l}\text { Neonatal } \\
\text { Hypoglycemia }\end{array}$} & \multirow[b]{2}{*}{$\mathrm{p}$-value } \\
\hline & & Yes & No & \\
\hline \multirow{3}{*}{ Gestationalage } & $>36$ weeks & 05 & 35 & \multirow{3}{*}{0.012} \\
\hline & 37-40 weeks & 21 & 66 & \\
\hline & $>40$ weeks & 13 & 17 & \\
\hline \multirow[t]{4}{*}{ Parity } & Primipara & 26 & 59 & \multirow{4}{*}{0.184} \\
\hline & Multipara & 10 & 48 & \\
\hline & Grand multipara & 03 & 11 & \\
\hline & Total & 39 & 118 & \\
\hline
\end{tabular}

\section{DISCUSSION}

Diabetes is a typical unexpected problem during pregnancy that leads to critical morbidities of the neonates. Inbabies of diabetic mothers, the hypoglycemia is a typical complication. In this study the frequency of neonatal hypoglycemia was observed among $24.8 \%$ of the cases. Similarly, Begum $S$ et al $^{13}$ reported that the Hypoglycemia was observed among $38.3 \%$ infants of the diabetes mothers. However, Saqib M et $\mathrm{al}^{14}$ observed lower rate of neonatal hypoglycemia as $14.8 \%$ among diabetes mothers. On the other hand, Magadla $Y$ et $\mathrm{al}^{15}$ reported Hypoglycemia in $39 \%$ of infants of diabetes mothers. Our findings are in consistent with those of Lodhi et $\mathrm{al}^{16}$ who reported hypoglycemia in $29.1 \%$ of neonates. Similar results were found in study conducted by the Khan let $\mathrm{al}^{17}$ who reported that $29.3 \%$ neonates were found to be hypoglycemic. And hypoglycemia was more common in males $(32.7 \%)$ as compared to females $(21.7 \%)$. Another study conducted by Atrushi $\mathrm{AM}$ et $\mathrm{al}^{18}$ reported that hypoglycemia was found in $17.78 \%$ of neonates.

In our study, average age of the women was $28.20 \pm 4.67$ years. On other hand Magadla $Y$ et $\mathrm{al}^{15}$ reported that the average maternal age was 33 years, with a range of 18-44 years. In the study of Begum $S$ et al ${ }^{13}$ reported that the majority mothers were between 21 and 40 years of age and mostly were multigravida, while in this study primiparous women were found in majority.

In this study, caesarean section was done in $62.4 \%$ cases. Study conducted by Begum $\mathrm{S}$ et $\mathrm{al}^{13}$ reported that around $96 \%$ of the neonates were delivered via C-sections and the average gestational age was around 36.5 weeks. However, in this study mean gestational age was $37.85 \pm 3.11$ weeks. On the other hand Imdad $S$ et al $^{19}$ reported that majority of infants were delivered through C- section i.e. 
$58.75 \%, 25 \%$ through SVD and $16.25 \%$ were instrumental deliveries.

In this study $92(58.6 \%)$ babies were male and $65(41.4 \%)$ were females. Similarly, Saqib M et $\mathrm{al}^{14}$ reported that out of all babies $66.5 \%$ were males and $33.5 \%$ were females. Pre-gestational and gestational diabetic incidence continues to rise all around the world. ${ }^{20}$ Accordingly, it is estimated that morbidities of the neonates neonatal like hypoglycemia, will also rise. The impacts of the prompt breast feeding on the neonatal hypoglycemia and the maternal long-term advantages is strongly linked to earliest start of breast feeding (particularly in diabetic mothers). ${ }^{20-22}$ However it is observed that the neonatal hypoglycemia of babies born to diabetic mothers can be corrected by early breast-feeding. ${ }^{20}$

\section{CONCLUSION}

As per study conclusion the neonatal hypoglycemia was observed to be highly prevalent among neonates of diabetic mothers as $24.8 \%$. It was found to be statistically significant according to gestational age. Based on strengths and weaknesses of our study we recommend future studies with large sample and multiple settings in order to reach to firm conclusion.

\section{REFERENCES}

1. Rani PR, Begum J. Screening and diagnosis of gestational diabetes mellitus, where do we stand. Journal of clinical and diagnostic research: JCDR. 2016 Apr;10(4):QE01.

2. Iqbal R, Jawaid S, Jabbar A, Qureshi R. Gestational diabetes mellitus--a forerunner of chronic disorders in mother and child. Journal of the Pakistan Medical Association. 2009;59(7):478

3. Iqbal R, Rafique G, Badruddin S, Qureshi R, Cue R, GrayDonald K. Increased body fat percentage and physical inactivity are independent predictors of gestational diabetes mellitus in South Asian women. Eur J Clin Nutr. 2007;61:736-42.

4. Stlund I, Hanson U, Bjorklund A, Hjertberg R, Eva N, Nordlander E, et al. Maternal and Fetal Outcomes if Gestational Impaired Glucose Tolerance Is Not Treated. Diabetes Care. 2003;26(7):2107-11.

5. Yang X, Hsu-Hage B, Zhang H, Zhang C, Zhang Y, Zhang C.Women with impaired glucose tolerance during pregnancy have significantly poor pregnancy outcomes. Diabetes Care. 2002;25:1619-24.

6. Vambergue A, Nuttens MC, Verier-Mine O, Dognin C, Cappoen JP, Fontaine P. Is mild gestational hyperglycemia associated with maternal and neonatal complications? The Diagest Study. Diabet Med. 2000;17:203-8.

7. Langer $\mathrm{O}$, Brustman L, Anyaegbunam A, Mazze $R$. The significance of one abnormal glucose tolerance test value on adverse outcome in pregnancy. Am J Obstet Gynecol $1987 ; 157: 758-63$
8. Metzger BE, Buchanan TA, Coustan DR. Summary and recommendations of the Fifth International WorkshopConference on Gestational Diabetes Mellitus. Diabet Care. 2007 30;Suppl 2:S251-S260.

9. The HAPO Study Cooperative Research Group. Hyperglycemia and adverse pregnancy outcomes. N Engl J Med. 2008;358(19):1991-2002.

10. Retnakaran R, QI Y, Sermer M, Connelly WP, Zinman B, Hanley JA. Isolated hyperglycemia at $1 \mathrm{~h}$ on oral glucose tolerance test in pregnancy resembles Gestational Diabetese mellitus in predicting post-partum metabolic dsysfunction. Diabet Care. 2008;31Suppl 7:1275-80.

11. Schmidt IM, Duncan BB, Reichelt JA, Branchtein L, Matos $\mathrm{CM}$, Fortie CA, et al. Gestational diabetes mellitus diagnosedwith a 2-hr $75 \mathrm{gm}$ oral glucose tolerance test and adverse pregnancy outcomes. Diabet Care. 2001; 24(7):1151-5.

12. Van Assche F, Holemans $\mathrm{K}$, Aerts L. Long-term consequences for offspring of diabetes during pregnancy. $\mathrm{Br}$ Med Bull. 2001;60:173-82.

13. Begum S, Dey SK, Fatema K. Neonatal glycemic status of infants of diabetic mothers in a tertiary care hospital. Indian journal of endocrinology and metabolism. 2018 Sep;22(5):621.

14. Saqib M, Jameel SA, Arif U, Anwar Z, Waheed S, Bashir M, Javed M. Hypoglycemia in Infants Born to Diabetic MothersA Tertiary Care Hospital Experience. Biomedica. 2019 Apr;35(2):98.

15. Magadla Y. Infants of diabetic mothers: maternal and infant characteristics and incidence of hypoglcemia (Doctoral dissertation).2016 https://core.ac.uk/download/pdf/188775973.pdf

16. Lodhi MA, Shah NA, Shabir G. Risk factors as-sociated with neonatal hypoglycemia. Profes-sional Med J 2006; 16: 68790

17. Khan I, Muhammad T, Khan MQ. Frequency and clinical characteristics of symptomatic hypoglycemia in neonates. Gomal Journal of Medical Sciences. 2010 Dec 31;8(2).

18. ATRUSHI AM. Frequency and risk factors of hypoglycemia in neonatal nursery in Duhok. ISRA Medical Journal. 2016;8(1):39-42.

19. Imdad S, Jabeen S, Yasmeen S, Subhani RU. Infant of Diabetic Mother Immediate Problems and Outcome. PJMHS 2016 Jul 1;10(3):913-5.

20. Cordero L, Ramesh S, Hillier K, Giannone PJ, Nankervis CA. Early feeding and neonatal hypoglycemia in infants of diabetic mothers. SAGE open medicine. 2013 Dec 19;1:2050312113516613.

21. Gunderson EP. Breast-feeding and diabetes: long-term impact on mothers and their infants. Curr Diab Rep 2008; 8: 279-286

22. Allen JA, Li R, Scanlon KS, Perrine CG, Chen J, Odom E, Black $C$. Progress in increasing breastfeeding and reducing racial/ethnic differences-United States, 2000-2008 births. MMWR. Morbidity and mortality weekly report. 2013 Feb 8;62(5):77. 